\title{
A Escala de Tons na Obra de Francisco de Lacerda
}

\section{J. M. Bettencourt da Câmara}

Só um conhecimento desigual dos grandes períodos da evolução da música ocidental ou, como acontece no caso de maus intérpretes, a prática duma execução musical que de todo prescinda dos valores da análise, nos levaria a supor a raridade do uso de acordes aumentados na história da música, ou ainda que apenas com o advento do simbolismo musical ${ }^{(1)}$ passaram os mesmos a ser utilizados. Sem incorrermos nem no limite nem no desvio apontados, salientemos, todavia, o que de significativo encerra o fato de, até as proximidades daquela corrente musical, o acorde aumentado surgir esporadicamente e - podemos decerto concluí-lo - como algo de marginal, até porque, menos raro em períodos e autores propensos à recusa da norma, do preceito escolar. A transgressão maneirista, o empenho romântico na inovação e, por parte de ambos os movimentos, a busca da intensidade expressiva, são atitudes propícias ao eclodir de fenômenos como o uso mais do que ocasional do acorde aumentado. Vejam-se, a título de exemplo das correntes mencionadas, o fragmento de Purcell Hear my prayer, o Lord, para coro a oito vozes (Fitzwilliam Museum, MS 88), onde proliferam os acordes aumentados, e o trecho pianístico de Franz Liszt intitulado As nuvens, que podemos considerar escrito na escala de tons. Se o último exemplo pode, ou deve, ser entendido dentro de um conjunto de características da obra de Liszt que a este conferem um estatuto de paternidade direta relativamente ao simbolismo musical e, relativamente ao romantismo em que se insere, o de especial papel na sua superação 
histórica (seja-nos relevada a linguagem hegeliana), o exemplo do compositor inglês do século XVII terá, por seu turno, que compreender-se de modo diverso - menos pelo prazer acintoso da transgressão, certamente, do que pela aposta em valores expressivos, impelindo o compositor a um mais amplo exercício da sua liberdade criadora.

Não se compreende o recurso sistemático por parte de músicos simbolistas aos acordes aumentados fora de uma larga perspectiva histórica que, significativamente, nos permite situá-lo no limite de um fenômeno de longa duração na história da música ocidental, o qual consiste na afirmação e desenvolvimento da tonalidade e se traduz na vigència exclusiva do sistema dualista dos modos maior e menor. Coincide este fenômeno, grosso modo, com o que na mais corrente periodização histórica se designa por Idade Moderna, embora no século XVII a tonalidade ainda se encontre em estruturação, libertanto-se progressivamente dos ditames da modalidade, e de muitos pontos de vista seja só no século XIX que ela atinja plena maturação (o significado da obra de Beethoven é aqui de citação obrigatória). Logrando, sob alguns aspectos, a sua plena realização no século XIX, a tonalidade entraria ainda nesse século, senão em processo de desintegração, pelo menos numa situação de "crise" que "anunciava" a sua negação por parte da que podemos tomar, de determinados pontos de vista, como a mais representativa conquista da linguagem musical no século XX. Referimo-nos ao atonalismo, naturalmente.

Se é por via do atonalismo que essa negação mais radicalmente se exprime, não podemos esquecer que dum mesmo esforço de renovação da linguagem musical participam outras tendências e movimentos desde as derradeiras décadas do século XIX, partindo mesmo, como acima lembramos, de orientações já contidas no romantismo musical. Prende-se esta questão, de fato, com o modo como devemos entender o simbolismo musical relativamente à chamada música moderna, que em boa parte se definiria pela recusa do subjetivismo romântico e afirmação dos diversos objetivismos musicais da primeira metade do século XX. Diremos que 
o simbolismo se encontrou numa via média entre o subjetivismo de Oitocentos e objetivismo de muita música do nosso século, ou, com Claude Rostand ${ }^{(2)}$, interpretaremos as palavras de Pierre Boulez "La flùte du Faune instaure une respiration nouvelle de l'art musical" como significando que, não menos do que Schoenberg e Stravinsky, embora não tão fragorosamente quanto eles, o autor de Prélude à l'après-midi d'un faune é, cronologicamente, o pórtico primeiro que abre para a modernidade musical? Indecidível, porventura, devido à ambigüidade mesma dos fenômenos históricos, este assunto importa para o conjunto de questões a que atenderá este breve ensaio.

Incompatível, num uso sistemático, com o sentido de uma tonalidade bem definida, não poderia o recurso à escala por tons inteiros, num contexto de vigência da tonalidade, ser senão ocasional. Caracterizam-se por uma impressão de vagueza os acordes obtidos a partir dessa escala. Verificando-se nela apenas terceiras maiores, os acordes de três sons cuja formação ela possibilita compreendem dois intervalos iguais (terceiras maiores, naturalmente), que nas suas inversões soarão identicamente à posição fundamental. A oitava divide-se em três terceiras maiores sobrepostas, propiciando a escrita, como é próprio da escala de tons, duplicidade enarmônica.

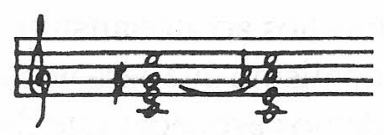

\section{Exemplo 1}

Verificam-se na escala por tons inteiros os seguintes intervalos: segunda e terceira maiores, quarta, quinta e sexta aumentadas, além da oitava perfeita. A exclusão dos demais intervalos que admite o sistema temperado (segundas e terceiras menores, sextas 
maiores e quartas e quintas perfeitas) não é sem conseqüências no que respeita às potencialidades harmônicas daquela escala.

Recordemos ainda que apenas duas escalas por tons inteiros podem formar-se,

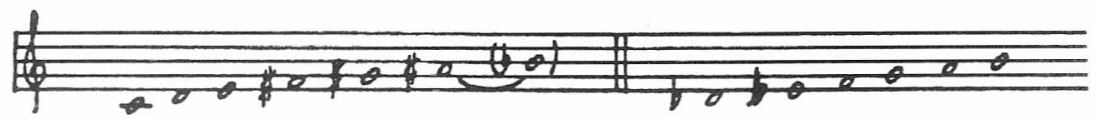

\section{Exemplo 2}

e que só quatro acordes diferentes obteremos a partir de ambas. Originando estas acordes compostos por terceiras maiores, são quatro os sons com que no âmbito desse intervalo deparamos para a funçăo de nota fundamental dos mesmos.

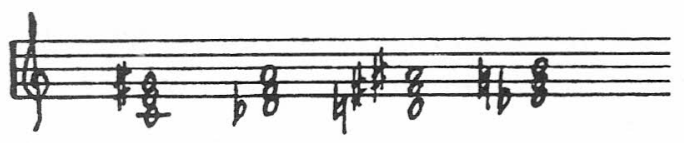

\section{Exemplo 3}

Comparando a estrutura das escalas tradicionais (modais e tonais) com a da escala por tons inteiros, parecerão as potencialidades daquelas e os limites desta decorrer do princípio de desigualdade, no primeiro caso, e de igualdade, no outro, que rege a relação entre os sons que as integram. Tudo se passa como se a natureza das escalas se achasse contida - ou pudesse exprimir-se - nas relações quantitativas que se verificam entre os sons que as constituem. A desigualdade inerente à existência de tons e meios-tons, no caso das escalas tonais e modais, dá azo às tensões características da harmonia que as tem por base. $\mathrm{Na}$ escala por tons inteiros, 
a igual divisão da escala origina a pobreza de possibilidades harmônicas, a platitude acústica, a simetria de relações que essencialmente reina entre os sons que a constituem.

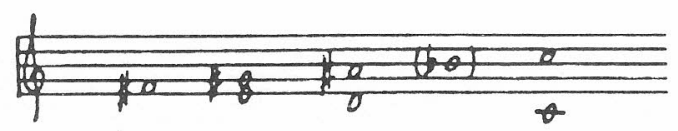

\section{Exemplo 4}

Determina, pois, o princípio de desigualdade que rege a formação das escalas modais e tonais tensões harmônicas que a escala de tons não poderia gerar. São, como todos sabemos mas neste contexto se impõe recordar, os intervalos de segunda menor entre determinados graus da escala que na harmonia tradicional (designêmo-la assim, aqui em mera oposição à harmonia baseada na escala de tons inteiros) funcionam como fator de maior tensão, o que se verifica maximamente no que podemos entender como o próprio cerne da harmonia tonal, isto é, na resolução do acorde da dominante, especialmente se provido da sétima, para o acorde da tônica. A relação atrativa - como a designaram alguns teóricos - do quarto ao terceiro grau e do sétimo ao oitavo, no caso das tonalidades maiores, ilustra bem essa relevância do papel dos meios-tons que, como sabemos, foram justamente entendidos, na pedagogia da harmonia funcional, como elemento fundidor da estrutura das escalas tonais e modais.

Impõe-se distinguir, como começamos por fazer, um uso fortuito dos acordes aumentados no âmbito duma prática harmônica anterior ao simbolismo, em que o seu aparecimento se verificará por força da busca de valores expressivos ou empenho na renovação da linguagem harmônica, do uso sistemático que nos permitirá, eventualmente, falar de ultrapassagem da tonalidade. Além do exemplo já citado da peça de Purcell, poderíamos, até 
finais do século XIX, alongar-nos na análise , ou mera referência a situações em que os acordes aumentados e, mais raramente, a escala de tons, surgem numa solução de enriquecimento da linguagem musical. O caso da alteração, ascendente ou descendente, da quinta do acorde maior (eventualmente guarnecido da sétima, se acorde da dominante) é dos mais significativos, surgindo em Ludwig van Beethoven (Quarteto op. $18 n^{\circ} 4$ ), Robert Schumann (Dichterliebe) e Johannes Brahms (Concerto $n^{0} 2$, para piano e orquestra), para citar, imprecisamente e quase ao acaso, alguns exemplos.

Resistindo à tentação de desvio relativamente ao assunto que o título em epígrafe circunscreve, e escusando outros exemplos que, reconhecemos, melhor serviriam o nosso intento, não deixaremos de aqui introduzir referencia a um dos mais famosos casos da história da análise musical, objeto que foi de incontáveis e desencontradas "leituras", desde Ernst Kurth, Arnold Schoenberg e Alban Berg (particularmente responsáveis pela idéia, que muitos professores se não coibem de repetir ainda, de que, no famigerado "acorde do Tristão", pois é dele que se trata, se encontraria decretada a morte da tonalidade - quando sabemos que o universo harmônico em que se move Richard Wagner é rigorosamente tonal e, como já outros referiram aliás, deparamos com momentos harmônicos idênticos em Beethoven, Mozart, Bach e mesmo Guillaume de Machault).

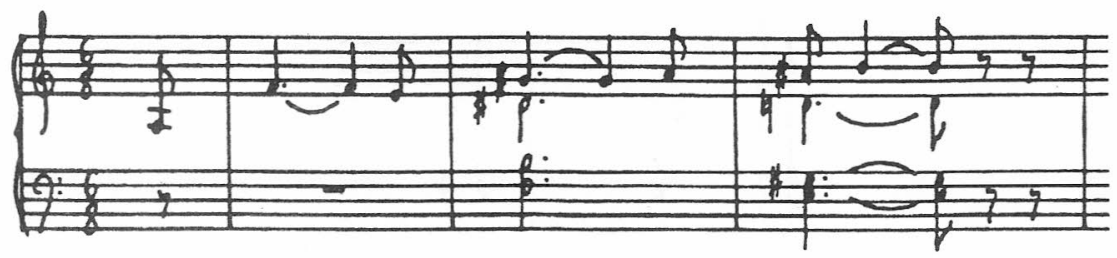

\section{Exemplo 5}

Chamaremos a atenção, rapidamente, para uma possibilidade de leitura da famosa passagem do Tristão e Isolda de Wagner que, 
mau grado a proliferação das perspectivas analíticas (se as conhecemos todas), julgamos não haver sido empreendida, salientando aspectos que se prendem com o tema deste pequeno ensaio. Não o tomamos, nem por isso, como exemplo excelente de pré-simbolismo na história da música européia, pouco convencidos também das razões que terão levado Richard Wagner a reivindicar-se, na famosa conversa com Renoir em Veneza, o estatuto de músico "impressionista".

Além da ossatura harmônica que poderá entender-se do seguinte modo

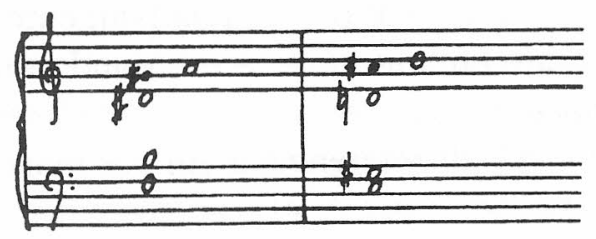

Exemplo 6

(não parece de duvidar que nos encontramos no tom de lá menor e, como já viram alguns dos muitos analistas do "acorde de Tristão" menos dados ao rebuscado, como Charles Koechlin e, também, Walter Piston, é o famoso aglomerado harmônico apenas uma "sexta francesa", afinal menos "complicada" do que quis Vincent d'Indy), atente-se nos dois acordes a partir de tons inteiros que é possível ouvir-se.

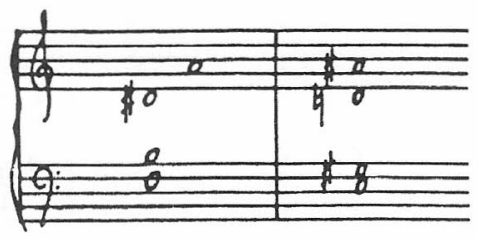

\section{Exemplo 7}

Não são, repetimos, Wagner e o seu Tristão e Isolda o autor e a obra que poderíamos aduzir como exemplo mais significativo 
e mais precoce do tema que nos ocupa. Não só pelos valores intrínsecos da sua obra e papel da mesma na superação do romantismo, mais ainda pelo que respeita concretamente ao nosso assunto, é bem maior a importância de outro compositor, que deveria ser sempre mais citado como tal do que como genial interprete que também foi. De fato, o contributo de Franz Liszt assume relevância maior do que o de Wagner, relevância patente não só no trechozinho para piano referido no início destas linhas, mas ainda em passagens de trabalhos doutra envergadura como a Sinfonia Fausto, sistematicamente escritas na escala de tons.

Igualmente importantes no processo de superação do romantismo, por um posicionamento estético que se consubstancia não só no nacionalismo mas ainda na recusa de excessos subjetivistas, os nomes dos Cinco Russos são de referência obrigatória no que respeita à questão de tons inteiros. Também Glinka na Abertura de Ruslan e Ludmila (1842) e Dargomisky em O convidado de pedra (1869) nos oferecem exemplos de uso sistemático da escala de tons que antecipam de várias décadas as realizações de Claude Debussy.

Seria necessário, porém, chegar a outras necessidades de expressão; a cultura européia teria de, ao nível da literatura e da pintura, cimentar outros afetos, para que a música, por seu turno, encontrasse na aplicação coerente da escala de tons e dos acordes aumentados, entre outros, os meios para corresponder musicalmente a traços da sensibilidade dos novos tempos. O que constituía os limites desse processo técnico, o que noutros contextos determinaria o seu uso restritivo ou mesmo a sua recusa, pode então ser maximamente explorado. O caráter de vagueza inerente à harmonia baseada nos tons inteiros, resultante, como ficou dito, da ausência de tensão gerada por uma desigual divisão da oitava, providencialmente virá ao encontro de uma outra sensibilidade estética, que excelentemente serve.

Não é por imposição de elucubrações teóricas, por elaboração prévia de sistemas artificialmente construídos, mas por intrínsecas necessidades de expressão que um criador com exigências de radical originalidade, como Claude Debussy, chega ao emprego 
sistemático de técnicas a que em menor extensão, como vimos, músicos anteriores já haviam recorrido. O que explica o sucesso, junto do músico que melhor realizaria o ideário estético simbolista, dessas técnicas é o acordo entre características e potencialidades delas e os objetivos prosseguidos por esse músico.

A análise da obra de Debussy, que fez largo uso da escala por tons inteiros (a que por isso alguns passaram a designar, na linguagem quotidiana, como "escala de Debussy"), demonstra por outro lado a consciência que tinha o compositor dos limites dessa possibilidade técnica. A escala de tons é apenas um dos vetores por onde se expande uma linguagem musical tão rica quanto original. Seria abusivo sobrevalorizar algum desses vetores quando, talvez mais do que qualquer outro dos músicos do seu tempo, Debussy vem impelir o desenvolvimento da linguagem musical em sentidos múltiplos - sendo um deles, não menos importante do que a harmonia baseada nos tons inteiros e o verticalismo da escrita dos acordes, o da revalorização da modalidade, como salientaram estudos pioneiros de Júlia d'Almendra ${ }^{(3)}$.

O que acaba de afirmar-se sobre Claude Debussy pode dizerse igualmente do músico cuja obra é o objeto destas linhas, o qual, contando na sua biografia com a coroa de glória de haver sido amigo do grande músico francês, não deixou de lhe sofrer influxo como compositor. Mais do que a descoberta, melhor dizendo, a aplicação sistemática da escala de tons, pesa a redescoberta da modalidade na constituição da linguagem musical de Francisco de Lacerda.

Tal não significa que seja de menosprezar o lugar que nessa obra é dado àquele elemento técnico. De certo ponto de vista ele revelar-se-á essencial, isto é, no que concerne à definição do lugar histórico em que o devemos situar, ao entendimento da sua obra no que respeita à questão da modernidade musical. Assomando no limiar desta, para recorrer à linguagem figurada, nesse limiar como 
que se mantém, exemplo, na história da música portuguesa, da ambiguiidade apontada no posicionamento do simbolismo musical no âmbito da revolução que no início do século XX se operou na música européia.

É, como veremos, quando se decide pela escala de tons, e menos quando se contenta com incursões por arcaísmos modais, que a sua pena mais flexivel se torna relativamente a conceitos tradicionais de (modos) maior e menor, tônica e dominante, tendendo a vencer os ditames de uma concepção funcional da harmonia. Com efeito, sem haver chegado a ultrapassar completamente esses conceitos, mesmo nos trechos em que mais sistematicamente utiliza a escala de tons, não deixou, o uso deste elemento técnico, de possibilitar-1he realizações marcadas de declarada ambigüidade.

Este posicionamento de eqüidistância, por assim dizer (ou de hesitação?), exprime-se igualmente em atitudes críticas assumidas pelo músico português que, tendo sido intérprete empenhado dos compositores do seu tempo (Debussy, Duparc, Chausson...), conhecendo algumas partituras de Stravinsky e Milhaud, não parece haver admitido tudo quanto, num último período da sua existência, os anos 20 e 30 deste século, lhe fornecia a produção dos músicos coevos. Não incluindo os manuscritos que deixou ${ }^{(4)}$ - ao contrário do que acontece para a obra de Henri Duparc, Claude Debussy, Manuel de Falla e outros - apreciações à arte de músicos como Schoenberg e os seus discípulos, de que certamente numa última etapa de vida, pelo menos quando de deslocações a França, para dirigir concertos, entre 1924 e 1927, não deixaram de chegar-lhe ecos - recordemos, de breves trechos satíricos sobre músicos portugueses do seu tempo, parte daquele que se refere a Luís de Freitas Branco: "Põe dissonâncias nas suas 'composições' como se elas tivessem bexigas loucas". Para além do caráter de verrina do texto a que pertence a frase citada, interessa aqui explicitar o pressuposto relativo à dissonância, que certamente Francisco de Lacerda continuava a só admitir em determinadas condições, 
deixando supor que muita da música de seu tempo que lhe era dado escutar fazia, em sua opinião, um uso incriterioso da dissonância.

Importa, para lhe definir o perfil, tanto o que um músico admite como aquilo que, com maior ou menor veemência, recuse. No que respeita às noções de consonância e de dissonância, parece seguro que Lacerda as mantinha como válidas, assim como ao preceito tradicional de que requer, a última, determinados cuidados no seu uso. Não repudia aliás o músico português, no trabalho do compositor, a larga experiência escolar que incluiu o seu percurso, mormente aquela que na Schola Cantorum de Paris ficou devendo a Vincent d'Indy; antes a conserva, sem prejuizo do acolhimento de contributos exteriores a ela, como é o caso do emprego alargado dos tons inteiros (significativamente não presentes em nenhuma das obras submetidas à apreciação de Vincent d'Indy que, com marcas da avaliação do mestre, chegaram até nós). É óbvio, aliás, que muito do rigor com que maneja esses novos elementos que integra em seu vocabulário, o deve ao treino a que, numa linguagem tradicional, o obrigou essa escolaridade.

Sem desconsideração da importância que para os músicos simbolistas assumiram os intervalos de quarta e quinta perfeitas, pode dizer-se que a segunda maior, a exploração acintosa do choque de segundas maiores, constitui uma das aquisições maiores da harmonia simbolista, ao passo que o gosto pelo choque harmônico de segunda menor e suas inversões (sétima maior e nona menor) seria reservado à mais declarada modernidade, por assim dizer - a de expressionismos (em parte) posteriores. Confirma-se, no caso de Francisco de Lacerda, que o choque de segundas maiores - naturalmente sem qualquer exigência do que nas categorias da harmonia tradicional se designava por preparação - é admitido sem reservas. Note-se, a título de exemplo, como se mantém, em três diferentes acordes consecutivos, o choque de segundas maiores entre as vozes mais graves da estrutura harmônica, na passagem seguinte, extraída de um dos trechos das Trente-six histoires pour amuser les enfants d'un artiste (Deux coqs, une poule... et ce qui s'ensuit, comp. 12): 


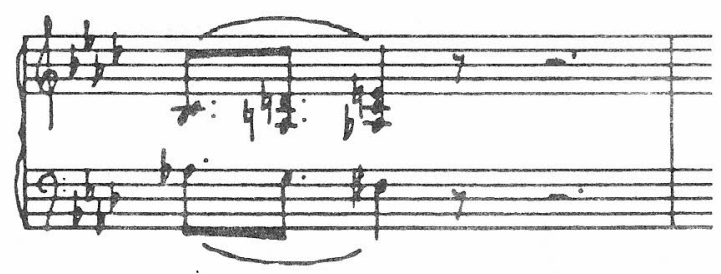

Exemplo 8

Por razão de fidelidade à sua formação, sensibilidade e opções estéticas, não poderia Francisco de Lacerda fazer uso, com o mesmo à-vontade, insistência idêntica, do choque harmónico de segundas menores. Referimos dois casos que parecem negar esta evidência, de novo em trechos das Trente-six histoires. Se em L'ours enchaîné (que, deixado incompleto pelo compositor, não pudemos incluir na nossa edição das Trente-six histoires, mas cujo manuscrito ali se reproduz em fac simile), o choque de meios-tons sobre graus consecutivos é sistemático e elevado a três diferentes sons - como que a exprimir o desconforto do urso acorrentado (comps. 1-10),
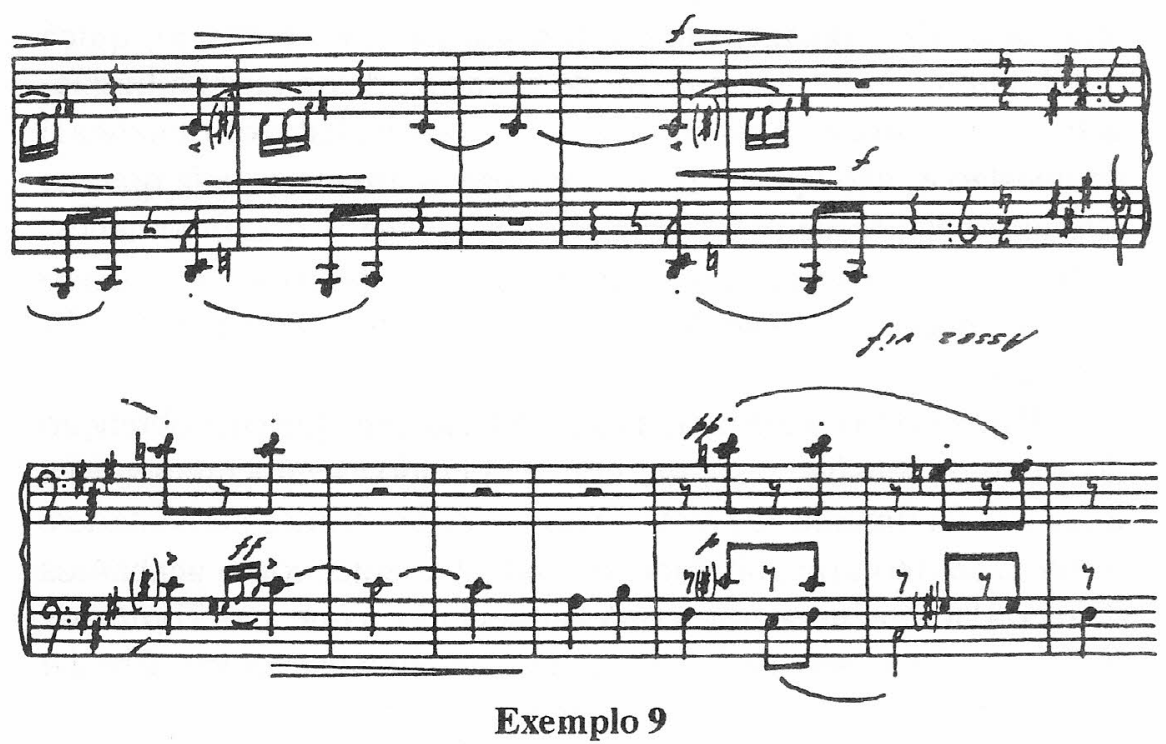
em La pie volée ocorre por força dos graus da escala sobre os quais se reproduz determinado aglomerado harmônico (comps. 1-2):

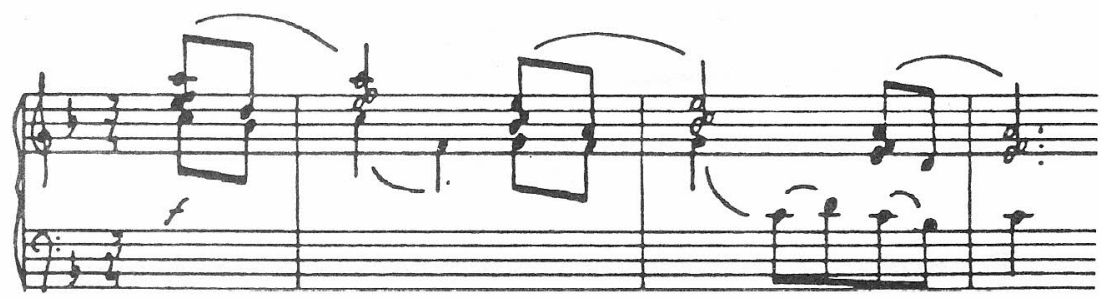

\section{Exemplo 10}

Antes de ensaiarmos uma breve perspectiva diacrônica da obra de Francisco de Lacerda do ponto de vista do nosso tema, buscando no percurso do homem a luz que sobre a obra ele possa projetar, procuremos evidenciar, pela análise das passagens de um dos mais significativos empreendimentos do compositor português, as Trente-six histoires, a que já recorremos, um duplo sentido inerente ao uso da escala por tons inteiros, isto é, a sua função de renovação da linguagem tonal, por um lado, e de ensaio, quiçá involuntário, de ultrapassagem, de negação, dessa mesma linguagem. Cremos que esta assumida perspectiva dualista (ou dialética!) da questão é, não apenas lícita, mas precisamente aquela que, na circunstância, respeita a intrínseca ambigüidade dos fenômenos. Referir-nos-emos imediatamente ao primeiro aspecto, abordando depois o que à dimensão de ultrapassagem, ou negação, da tonalidade diz respeito.

Parece ser a escala menor dita artificial (em que para obtenção do efeito de sensível o sétimo grau é alterado ascendentemente) a que mais facilmente se presta à formação de acordes aumentados. Sobre o sétimo grau, alterado ascendentemente, como acabamos de recordar, obtém-se um acorde aumentado, a que, nas Trente-six histoires, Francisco de Lacerda freqüentemente recorre. Em La levrette russe por diversas vezes (comps. 2, 5), 


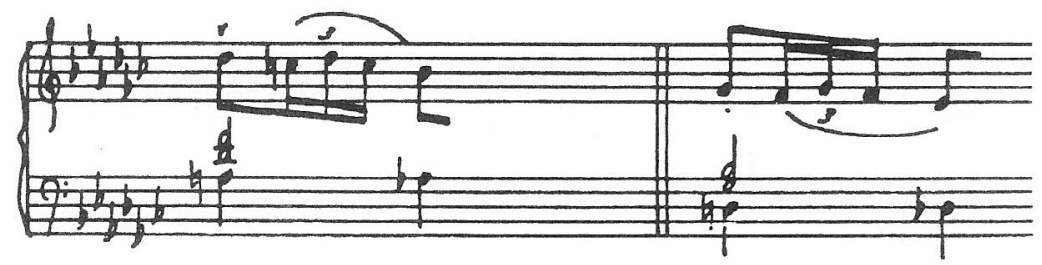

Exemplo 11

e em Tourterelles (comp. 17).

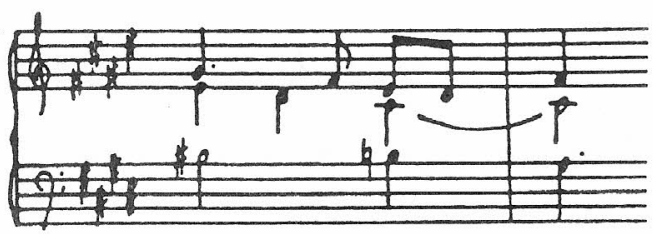

Exemplo 12

Do terceiro ao sétimo graus, fornece-nos a referida escala, pela alteração ascendente do sexto e sétimo graus, uma seqüência de quatro segundas maiores que, alargando o efeito do trítono, é particularmente cara à sensibilidade simbolista. Veja-se o mussorgskiano Maître Corbeau, I (comp. 6):

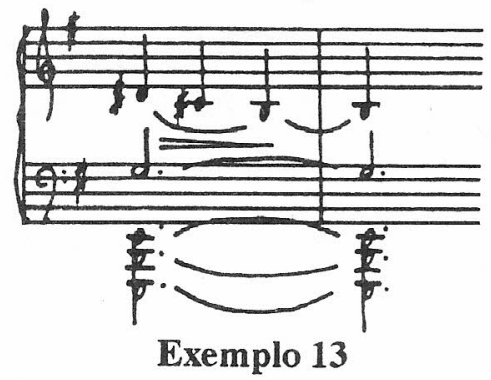

Nas tonalidades menores ainda, o acorde da dominante permite, por via da substituição da quinta pelo grau imediatamente superior, um acorde aumentado. É um dos casos harmônicos mais freqüentes na obra do compositor (saliente-se a importância, de algum modo estrutural, que tem no trecho sinfónico Almourol). Das Trente-six histoires, de novo Deux coqs, une poule... et ce qui s'ensuit, onde abunda o acorde em questão (comp. 5): 


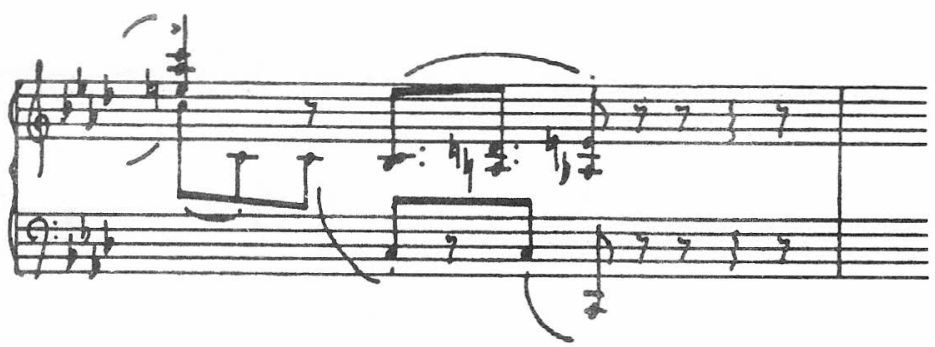

Exemplo 14

Estamos, no caso de Deux coqs, une poule... et ce qui s'ensuit, perante uma peça, como a análise inequivocamente confirma, na tonalidade de fá menor que, por práticas idênticas a esta, se renova, se tinge de nítidas cores simbolistas, afastando-se dos usos clássicos da tonalidade.

Também o gênero cromático parece propício à obtenção de formações harmônicas a partir de tons inteiros. Bom exemplo disso é o tema que, visto o fato de o haver utilizado em várias obras ${ }^{(5)}$, Francisco de Lacerda deve ter considerado uma das suas melhores trouvailles: Le ramier blessé (comps. 1-6).

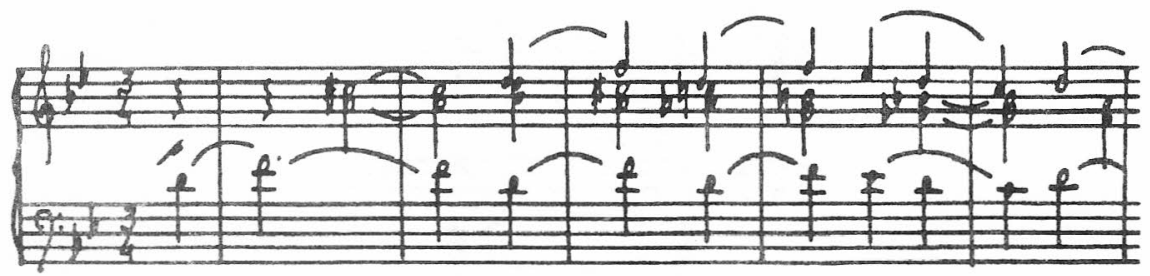

\section{Exemplo 15}

Aqui, à melodia - que, de acordo com o gosto do autor por um assumido elementarismo harmonico, se desdobra em oitavas nas duas vozes extremas - contrapõe-se o movimento descendente das terceiras maiores, deslizando cromaticamente de modo a formarem, com a melodia, acordes aumentados. 
No exemplo seguinte (La pieuvre, comps. 4-6),

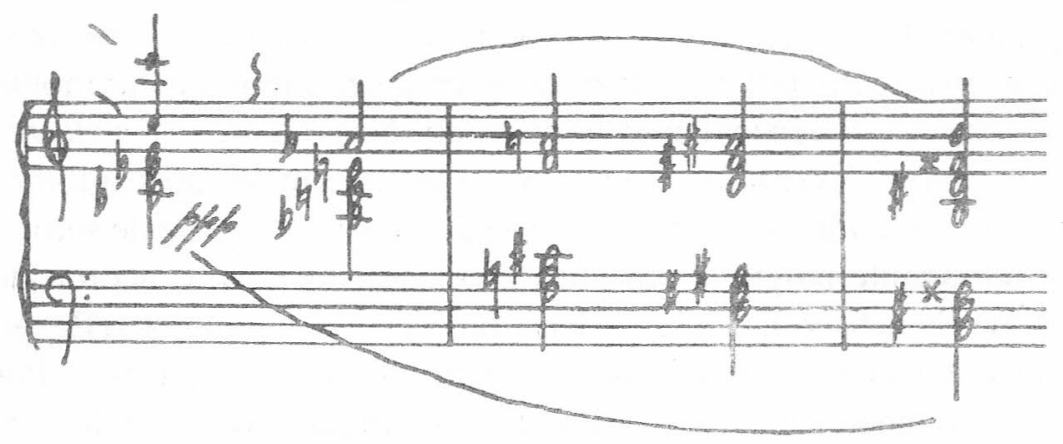

Exemplo 16

ao movimento cromático ascendente da voz superior opõe-se o movimento descendente da voz inferior. O fato de este último se processar segundo o intervalo de terceira menor possibilita o aparecimento dos quatro únicos acordes que é possível formar a partir das duas escalas de tons, como antes referimos (a processarse segundo o intervalo de terceira maior, escutariamos sempre o mesmo aglomerado harmônico, recorde-se).

Deparamos, no caso seguinte, com o recurso aos mesmos quatro acordes, para além da movimentação cromática das vozes extremas. De passagem, noțe-se ainda, no segundo acorde reproduzido, o procedimento enarmônico que leva a escrever o mesmo som no sentido ascendente com o sinal de sustenido e no sentido descendente com o de bemol (Deux coqs, une poule... et ce qui s'ensuit, comps. 20-21).

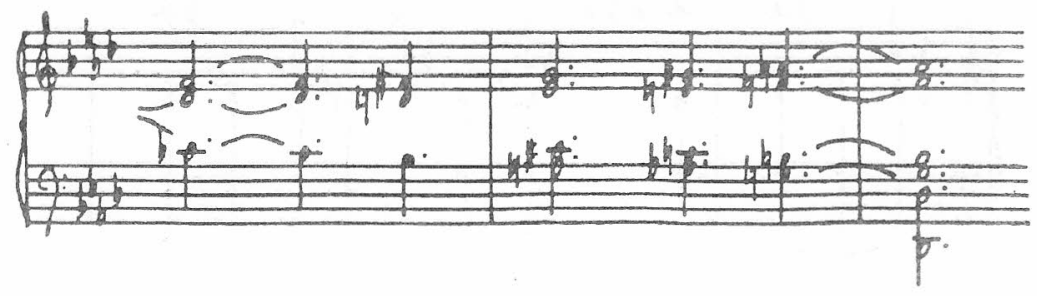

Exemplo 17 
É freqüentíssima, na obra de Francisco de Lacerda, a movimentação cromática, ascendente ou descendente, de um mesmo aglomerado sonoro, constituído ou não a partir da escala de tons, de acordo com um dos princípios característicos da harmonia simbolista - o verticalismo harmônico. Nas Trente-six histoires pour amuser les enfants d'un artiste, identificam-se esses aglomerados submetidos a deslocação cromática com o acorde de sétima da dominante nalguma das suas inversões, ou com o acorde de sétima da sensível, o que poderia propiciar-nos alguma reflexão (por quê este tipo de aglomerado harmônico e não outros?). Por vez $\mathrm{s}$, a opção vai para acordes em cuja origem podemos descortinar, com alguma ambigüidade, a escala de tons. Exemplificam-no casos como o seguinte, onde é nítida a estrutura da melodia acompanhada (Le phoque jaloux, comps. 15-16),

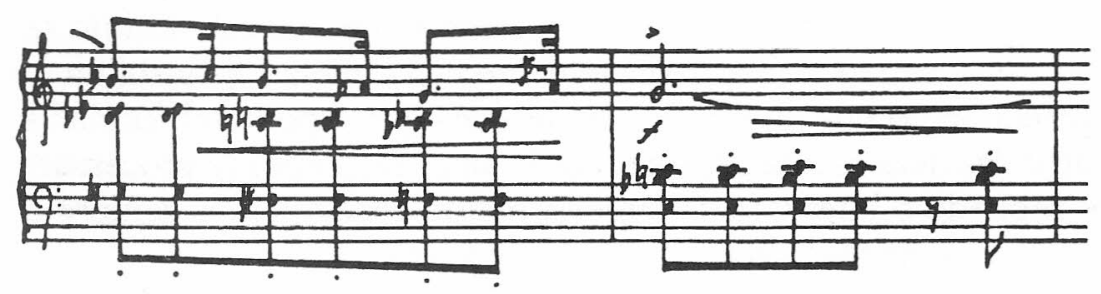

\section{Exemplo 18}

ou, ainda, de Mon chien et la lune (comps. 10-12).

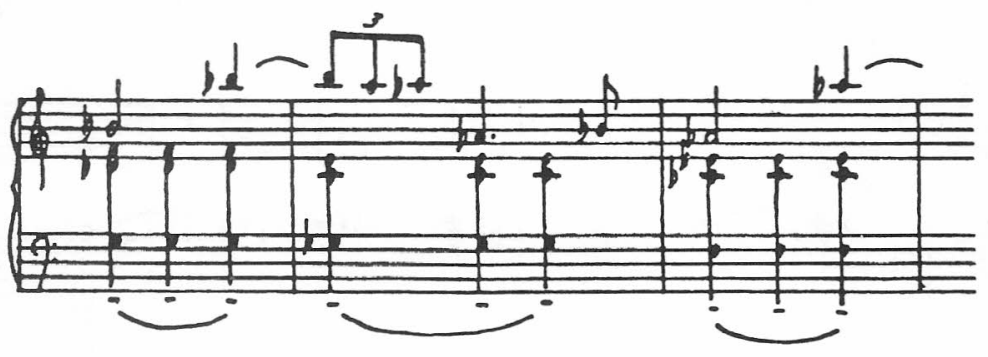

Exemplo 19 
No exemplo seguinte o mesmo aglomerado harmônico movese cromaticamente dentro do âmbito de uma dupla pedal da tônica das duas vozes extremas (Le cerf blessé, comps. 9-12).

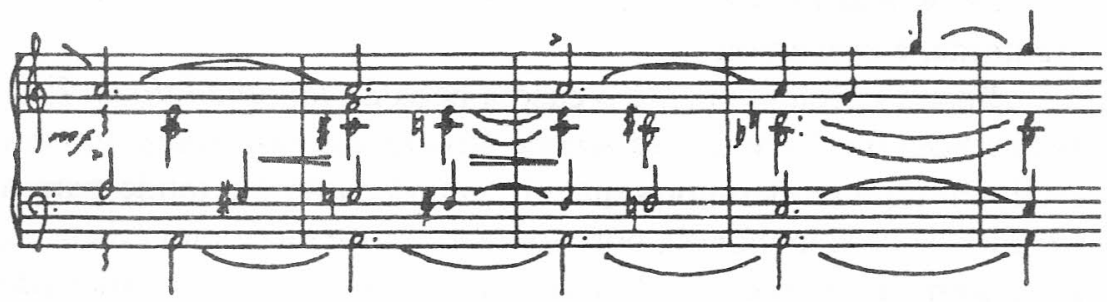

Exemplo 20

Como acabamos de constatar por via do exemplo de alguns trechos das Trente-six histoires pour amuser les enfants d'un artiste de Francisco de Lacerda, o recurso à escala por tons inteiros e aos acordes aumentados funciona como fator de renovação da tonalidade, que assim se adapta a traços de nova sensibilidade musical que se afirma por fins do século XIX e princípios do século XX. Sem contradição, podemos entendê-lo também como fator de dissolução do idioma tonal. É este aspecto, de algum modo negativo (relativamente à subsistência da tonalidade), indissociável do primeiro, podendo descortinar-se em qualquer das peças que já citamos; torna-se, porém, mais evidente em outros trechos das Trente-six histoires, que de fato nos parecem ilustrar melhor uma dimensão de desagregação do sistema tonal igualmente inerente ao uso da escala de tons, sem que disso, porventura, tivessem nítida consciência os seus agentes, os compositores.

Esta ação dissolvente da escala de tons relativamente à impressão tonal traduz-se no atenuamento da noção de modo maior e modo menor, como do conceito de tônica. Na obra de Francisco de Lacerda, mesmo nos trechos que mais longe vão nesta matéria, jamais deparamos com atonalidade franca, com a absoluta ausência de um som que de algum modo polariza o discurso musical, como sol de um sistema em torno ao qual giram planetas ou, em linguagem menos figurada, como ponto de partida que será, por neces- 
sidade, também ponto de chegada. Mau grado isso, encontramos nas Trente-six histoires trechos, ou passagens, onde é notável a ambigüidade conseguida - decorrente, de algum modo, da natureza dos meios escolhidos (no caso, a escala de tons), mas também assumida, e procurada.

Ilustra excelentemente o caso a peça Le phoque jaloux. Embora a nota fundamental do acorde em que ela expira seja um dó, facilmente pretenderíamos que em seu decurso ela tende para a tonalidade de lá menor ou, por momentos, a de mi (maior/menor), para além de momentos de mais óbvia intenção modulante (dó sustenido menor?). O que importa é que, num pequeno trecho, de apenas trinta e dois compassos, a hesitação, a ambivalência, quanto a estas questões, são tais que em nenhum momento podemos afirmar seguramente uma tonalidade óbvia, e uma única tônica. Outras peças, na coletânea, ilustrariam este mesmo fenômeno de fuga a uma tônica evidente, de procura, antes, da oscilação, do "espaço" entre múltiplas tônicas. É o caso já citado de Le ramier blessé, onde só os compassos finais nos confirmarão na tonalidade de sol menor, até lá permanecendo uma indefinição ostensiva entre aquela tonalidade e o tom, talvez com maior precisão, um modo com tônica em ré, para que mais naturalmente desde o início nos inclinaríamos. Em La pieuvre verifica-se o fato eloqüente de, numa peça que efetivamente não sabemos se escrita nos tons (medos?) de si ou mi, o compositor, bem conseqüentemente, nem chegar a definir a armação da clave, contentando-se com escrever alterações (sustenidos ou bemóis) à medida que as mesmas ocorrem. Este é talvez o caso mais significativo que, no que concerne a esta questão, encontraremos em toda a coletânea; outros, todavia, depararemos, como por exemplo Complaîntes de la chèvre que, como em volume consagrado à obra pianística de Lacerda já dissemos ${ }^{(6)}$, pode propiciar análises curiosas quanto a questões de tonalidade, modalidade, tônicas...

Não é sem intenção que, antes de empreendermos um percurso cronológico da obra de Francisco de Lacerda segundo o tema escolhido para este artigo, concentramos a nossa atenção, para 
ilustrar aspectos do trabalho do compositor com a harmonia baseada nos tons inteiros, numa recolha de trinta e seis breves peças para piano cujo interesse, a um olhar distraído, se esgotará no uso pedagógico que lhes fosse dado. O fato de constituírem, nas palavras do próprio autor (7), umas "pela intenção, 'figurinhas de passar' sonoras; outras, suaves descritivos dum gesto melódico apenas perceptível", não significa que nelas menos se tenha empenhado o compositor. Com efeito, inclui a coletânea algumas das melhores realizações de Francisco de Lacerda. Se no seu texto tanto chega a análise a explicitar, é porque nelas muito foi investido, muito tendo a dar à vivência e à compreensão musicais.

É altura de encerrarmos estas páginas com a anunciada perspectiva da produção musical de Francisco de Lacerda do ponto de vista de uma das mais características aquisições de linguagem da corrente em que globalmente se insere esta produção. Como vimos, o tema dos tons inteiros propicia fecunda reflexão sobre um entendimento histórico largo dessa mesma corrente: a sua relação ao que no tempo musical europeu a precede e ao que ela como que preludia, a modernidade musical.

A abordagem diacrônica duma obra proporciona, senão postula, a busca na história - no autor e no meio - de fatores que the expliquem as características, a adoção deste e daquele elemento de linguagem. O que não deixa de pressupor questões fundamentais, hoje, para nós, mais claras enquanto tais, isto é, enquanto questões, eventualmente indecidíveis, não resolúveis por conjuntos mais ou menos coerentes de certezas que caracterizaram correntes de um passado assaz próximo de nós. Positivismos, marxismos, historicismos são aliás, nesta como noutras matérias, parcialmente subsidiários uns dos outros, encontrando-se por vezes, mau grado oposições de primeiro plano, em inesperados acordos profundos. Fiquemo-nos pelas questões. 
Até que ponto fornecerá a biografia, o percurso do homem, luz que ilumine (explique?) os contornos da obra? Que acordos chegaremos a descortinar entre as características da obra e os acontecimentos vividos pelo homem que a fez, entre o seu perfil caracteriológico e a produção artística que deixou? No caso de Francisco de Lacerda, até que ponto o conhecimento de Debussy e da sua obra explicará a adesão ao simbolismo musical? Poderia, é verdade, o músico português ter-se mantido fiel à estética do último romantismo agradecido à figura e ao magistério de Vincent d'Indy, a quem humanamente tanto ficou devendo...

Questões velhas que, como dissemos, mais nos interessam enquanto questóes do que a parcialidade das respostas que lhe têm sido dadas. Seja-nos permitido, contudo, frisar que a generalizada tendência determinista que, no que respeita à compreensão das criações do homem, herdamos do século passado, e nos leva a "explicar" a obra de arte por conceitos como meio geográfico, estrutura social, condições psicológicas do indivíduo criador, e mesmo raça, não parece chegar a explicar a criação cultural, não salvaguardando geralmente a especificidade desta relativamente aos fenômenos da natureza, não reservando espaço suficiente à consideração de um fator essencial da mesma, que é a liberdade criadora. Não basta, como é sabido, embora tanta vez ainda se esqueça, a verificação das influências à explicação da obra artística; todavia, que parte de verdade nos podem elas ainda conceder na obtenção desse objetivo, é questão que, apesar de tudo, devemos continuar a pôr-nos.

Se não chegamos a entender a obra de Francisco de Lacerda sem a faculdade de escolha do homem que ele foi, sem a dimensão de contingência e gratuidade que nela apreendemos, é verdade também que parece excessivo por isso escusar de todo a perspectiva que se firme no relacionamento dos traços da obra ao perfil do homem e aos eventos do seu percurso. Não precisava Francisco de Lacerda (1869-1934) de fixar-se em Paris em 1895 para que na sua linguagem musical da maturidade viesse a integrar como importante elemento técnico a escala de tons. Tal não quer dizer que toda 
a parte da sua existência fora de Portugal, em França e na Suíça, o contato com obras e autores contemporâneos, não hajam atuado como impulso à descoberta das potencialidades do referido elemento técnico.

O músico português chega a Paris alguns meses depois da primeira audição do Prélude à l'après-midi d'un faune (1894), quando o autor desta obra, que podemos entender como verdadeiro manifesto histórico do simbolismo musical, ultimava a primeira versão de outra das suas obras maiores - Pelléas et Mélisande. Só em 1904 conhecerá pessoalmente Claude Debussy, mas antes disso escuta alguns dos seus trabalhos (sabemos haver assistido a uma das primeiras audições de Pelléas et Mélisande, em 1902). No Conservatório de Paris (1895-1897) fora condiscípulo de Maurice Ravel, a cujos primórdios de compositor assistirá, não sem alguns comentários céticos ainda por revelar ${ }^{(8)}$.

É significativo - e compreensivel - que na obra do compositor português, até 1902, poucos sinais se vislumbrem de acordes aumentados. Dependente - tanto pelos estudos que fizera em Lisboa, como pelos que levara a cabo no Conservatório de Paris e mesmo, depois, na Schola Cantorum - duma retórica romântica tardia, onde as sombras tutelares de Schumann e Chopin se projetavam menos do que o influxo de músicos como Heller (cujas Nuits blanches o jovem Francisco de Lacerda interpretava), não admira que a análise harmônica dos seus primeiros trabalhos nos revele marcas da descoberta de inovações desse tipo. No Conservatório parisiense, cujo ensino Lacerda não apreciou, mau grado o respeito que lhe merecia seu mestre de órgão Charles Widor, é fácil supor que a estética imperante, dominantemente operática e conservadora, não correspondia à natureza profunda do músico português. Quanto às orientações vigentes na Schola Cantorum, onde a partir de 1902 será por alguns anos também professor, uma convicta adesão inicial só se manterá parcialmente, quando progressivamente Francisco de Lacerda vai descobrindo opções artísticas em boa parte alheias à escola da Rue de Saint Jacques, marcada sobretudo pela vigorosa personalidade de Vincent d'Indy. 
De quanto lhe cedeu a Schola Cantorum, Lacerda manterá ao longo da sua vida o culto dos grandes mestres do passado, entre todos pontificando João Sebastião Bach, a redescoberta do que hoje designamos por "música antiga" e a importância, a vários títulos, da canção popular. É assim que, submetido à perspectiva historicista do ensino da composição que caracterizava a pedagogia de Vincent d'Indy, Lacerda produz obras que surgirão como pastiches das de João Sebastião Bach (dois Corais variados, para órgão, suítes "dans le style ancien") e tentames de realização do princípio cíclico de César Franck, assumido pelos discípulos fundadores da Schola Cantorum (um andamento de Sonatina).

A linguagem harmónica destas obras, e de algumas dos anos subseqüentes a 1902 , sem prejuízo do aparecimento esporádico de algum acorde aumentado, não é inovadora. As aquisições de linguagem que o integrarão na arte característica do seu tempo, que dele farão um criador de perfil inequivocamente simbolista, encontra-las-á fora da Schola Cantorum. A oposição entre Vincent d'Indy e Claude Debussy, que marca a vida musical parisiense de começo do século, é também nítida na biografia de Francisco de Lacerda, sem prejuízo do relacionamento que, pelo menos durante algum tempo, com ambos manterá. "Le genre franco-flamand", como o designará, merecer-lhe-á fortes reservas, que contrastam com o superlativo encômio que nos seus escritos é feito à arte de Debussy.

Considerava Francisco de Lacerda 1902 como ano de viragem na sua vida, tendo dessa data dito mais tarde: "Je rentre en moi même". O sentido da afirmação é largo, aplicando-se a toda a existência do músico português ${ }^{(9)}$, mas ganha verdade maior, porventura, no que respeita ao seu evoluir como compositor. Não nos cansamos de chamar a atenção para o significado de que se reveste a composição nesse ano, em Paris, do curto trecho para piano Les oiseaux qui s'en vont pour toujours que, meses depois, definido o projeto das Trente-six histoires pour amuser les enfants d'un artiste, integrará a coletânea ${ }^{(10)}$. Marca este trecho, verdadeiramente, a emergência da modernidade simbolista na música 
portuguesa: mais do que a opção pela modalidade, consideramos representativo do fato o uso convicto dos acordes aumentados na segunda parte da peça.

Nos anos subseqüentes, em que é sucessivamente chefe de orquestra em Nantes, Montreux e Marselha, a opção de Lacerda como criador musical cimentar-se-á, o que é sem dúvida merecedor de nota, se lembrarmos que a profissão abraçada lhe impunha a execução de obras exteriores a essa opção estética (sem que por isso tenha deixado de tornar-se excelente intérprete das mesmas). Dentro da gama de opções que lhe oferece o tempo e o meio em que vive, o compositor português segue a orientação que mais fecunda lhe parece e, certamente, melhor correspondia à sua própria natureza.

Curiosamente, da obra que o aproximará de Claude Debussy estão ausentes os tons inteiros. À Danse du voile, que em 1904 apresentará a concurso promovido pela Revue musicale, Debussy e Vincent d'Indy, presentes no júri, atribuirão o único prêmio, louvando na peça para piano "a firmeza rítmica e a frescura de inspiração" (11).

Também na obra para canto e piano deste grande período da sua vida (que se prolonga de 1895, data da partida para Paris, a 1913, data do regresso aos Açores) pouco figuram os tons inteiros, que para a voz, efetivamente, são menos "naturais". Sobre texto francês, obedecendo aos parâmetros estéticos da "mélodie", não parecem estes trabalhos dever muito às realizaçōes debussistas para esta formação, mesmo uma formosa e larga Berceuse para contralto e piano, a partir de poema extraído das Chansons de Bilitis de Pierre Louÿs, a qual julgamos o trecho mais recente deste conjunto (composto decerto entre 1910 e 1913).

O mesmo poderá adiantar-se sobre um segundo setor da sua produção para canto e piano, dos anos 20 , dominado por uma orientação estética nacionalista. Aqui pontificam as Trovas, como é conhecido, e nestas as necessidades de definição tonal ou modal que a natureza vocal da obra aconselha, assim como a referência ainda que "sublimada", não literal - ao folclore musical português, 
não permitem mais do que o uso ocasional de algum acorde aumentado na parte pianística.

É, com efeito, em obras de destino instrumental que Lacerda faz uso mais amplo dos tons inteiros. Ainda dos anos de Montreux (cremos que de 1911), na música de cena para a peça de Maeterlinck $A$ Intrusa tem lugar considerável a escala dos tons. Trata-se de páginas exclusivamente orquestrais, a que associa o texto declamado da obra literária.

As peças para orquestra posteriores inserem-se igualmente no idioma musical do seu tempo, integrando as aquisições harmônicas do simbolismo musical, como os acordes aumentados e as passagens melódicas por tons inteiros. Saliento aquelas onde estes processos são talvez mais abundantes: Epitaphe - Sur la tombe d'un héros, escrita nos Açores em 1915 (note-se o trítono dos compassos iniciais...), Almourol (1926) e, sobretudo, Pantomima, que resulta da orquestração de passagens do bailado La force e de Le ramier blessé das Trente-six histoires pour amuser les enfants d'un artiste. Inscrevem-se quase integralmente na técnica dos tons inteiros tanto Pantomima como La force. É esta a peça que, na versão pianística em que chegou até nós, pela primeira vez publicamos, a encerrar o presente estudo ${ }^{(12)}$ 


\section{NOTAS}

1) Depois de, em escritos anteriores, haver cedido à terminologia estabelecida, resolveu recentemente o autor deste breve ensaio substituir a expressão "expressionismo musical" pela de "simbolismo musical", sem dúvida mais adequada à essência da arte de músicos como Claude Debussy e, no âmbito da histórica da música portuguesa, Francisco de Lacerda.

2) Claude ROSTAND, Dictionnaire de la musique contemporaine. Paris, Larousse, 1970.

3) Júlia d'ALMENDRA, Les modes grégoriens dans l'oeuvre de Claude Debussy. Paris, Librairie Gabriel Enault, 1950.

4) Francisco de LACERDA, Escritos sobre música. A editar brevemente pela Direcção Regional dos Assuntos Culturais (Açores), com introdução, fixação do texto e notas de J. M. Bettencourt da Câmara.

5) Com efeito, Francisco de Lacerda usa o tema de Le ramier blessé na peça orquestral Pantomima, além de uma adaptação do mesmo intitulada Estudo, para violoncelo e piano.

6) J. M. Bettencourt da Câmara, A mísica para piano de Francisco de Lacerda. Lisboa, Instituto para a Cultura e Língua Portuguesa, 1987. Col. Biblioteca Breve, $\mathrm{n}^{\circ} 111$.

7) Trata-se do texto de apresentação de algumas das peças das Trente-six histoires pour amuser les enfants d'un artiste publicadas, em fac-simile de cópia do autor, na revista Contemporânea, $\mathrm{n}^{\circ} 3$, julho de 1922 (Lisboa).

8) Em apontamento com data de 6 de janeiro de 1906 Francisco de Lacerda escreveu: "Société Nationale (Salle Erard). De l'abondant programme, je retiens le 'Miroirs' de M. Ravel. Ce petit bonhomme a, évidemment, du talent. Un talent assez particulier, assez spécial; un talent à la Caran d'Ache. Un singe très bien dressé. Plus que ça, peut-être.

Il a le sens de la caricature.

Je lui est (sic) conseillé (chez les Cruppi) de faire quelque chose sur 'Don Quichote'. Cela lui conviendrait certainement. Mais... le comprendrait-il, le sublime monument de la littérature espagnole? Le pire c'est qu'il a du talent, des 'ressources', mais qu'il est peu intelligent et d'une ignorance honteuse. Très ordinaire, presque vulgaire, il surprend par ses élans, ses sacades, de bon goût. Avoir du talent ou du génie, c'est quelque chose de très étonnant... Cela pousse comme pousserait une belle fleur sur un rocher aride et nụ...

La 'Barque sur l'Océan' de ces 'Miroirs', ainsi que l' 'Alborada' ce sont des choses qui éxistent, de très belles choses." 
9) Lembremos que por volta de 1901-1902 se define a sua opção profissional pela direção de orquestra.

10) Quando em 1902 escreve Les oiseaux qui s'en vont pour toujours, não parece que Francisco de Lacerda possuísse já idéia da que se tornaria na sua obra pianística maior. É de 1903 o projeto de uma obra lírica que se chamaria Madressilva - Conte pour amuser les enfants d'un artiste, onde julgamos ter origem o título da coletânea para que escreve vários trechos já em 1907, na Suíça.

11) Revue musicale, Paris, 1 de abril.

12) Por nós recuperada a partir do manuscrito autógrafo, La force foi executada em primeira audição absoluta pelo pianista José Eduardo Martins no programa dos seus recitais em Santos, São Paulo e Ribeirão Preto, integrados no Festival Música Nova de 1992 (agosto).

J. M. Bettencourt da Câmara, Compositor, Professor e Musicólogo português, é autor de obras significativas sobre o compositor Francisco de Lacerda. 
Francisco de Lacerda

Donné: - La "force brute", la créature armée, bardée de fer. Révélation d'autre chose. Peu à peu Elle se dépouille de ses armures, de son air féroce et dominateur, et, dans une poussée ascentionelle, Elle s'illumine et révèle l'Intelligence.

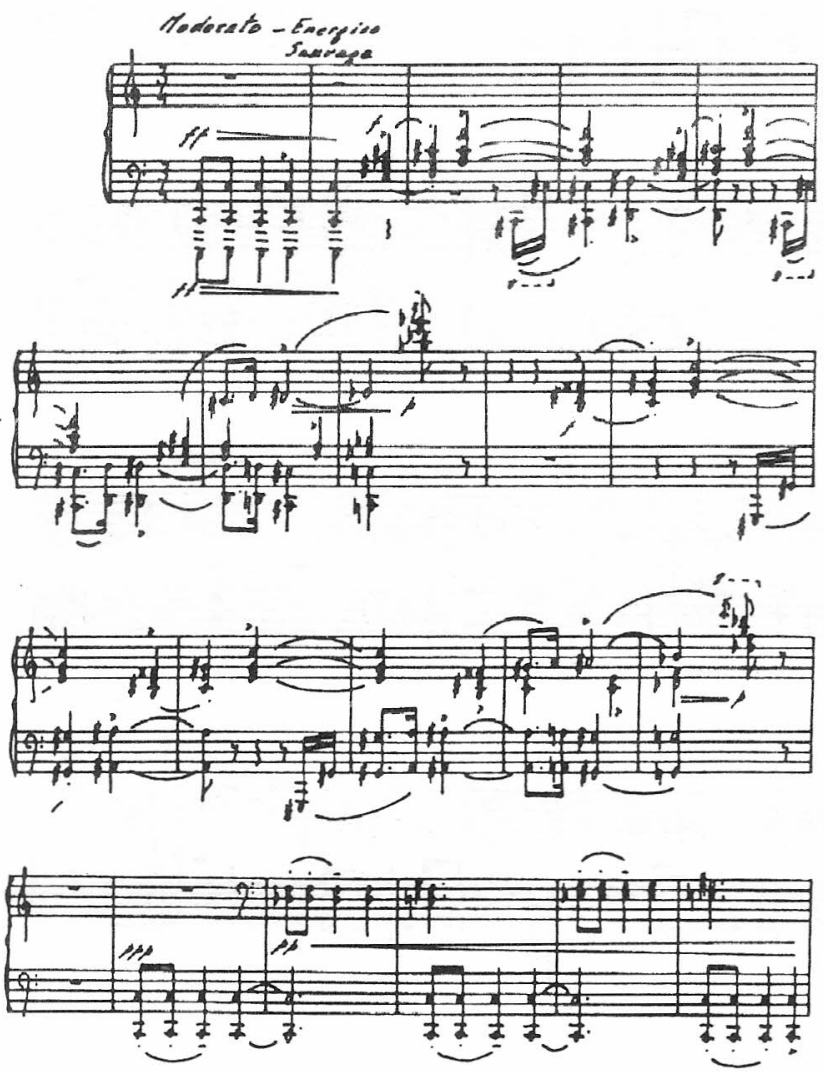



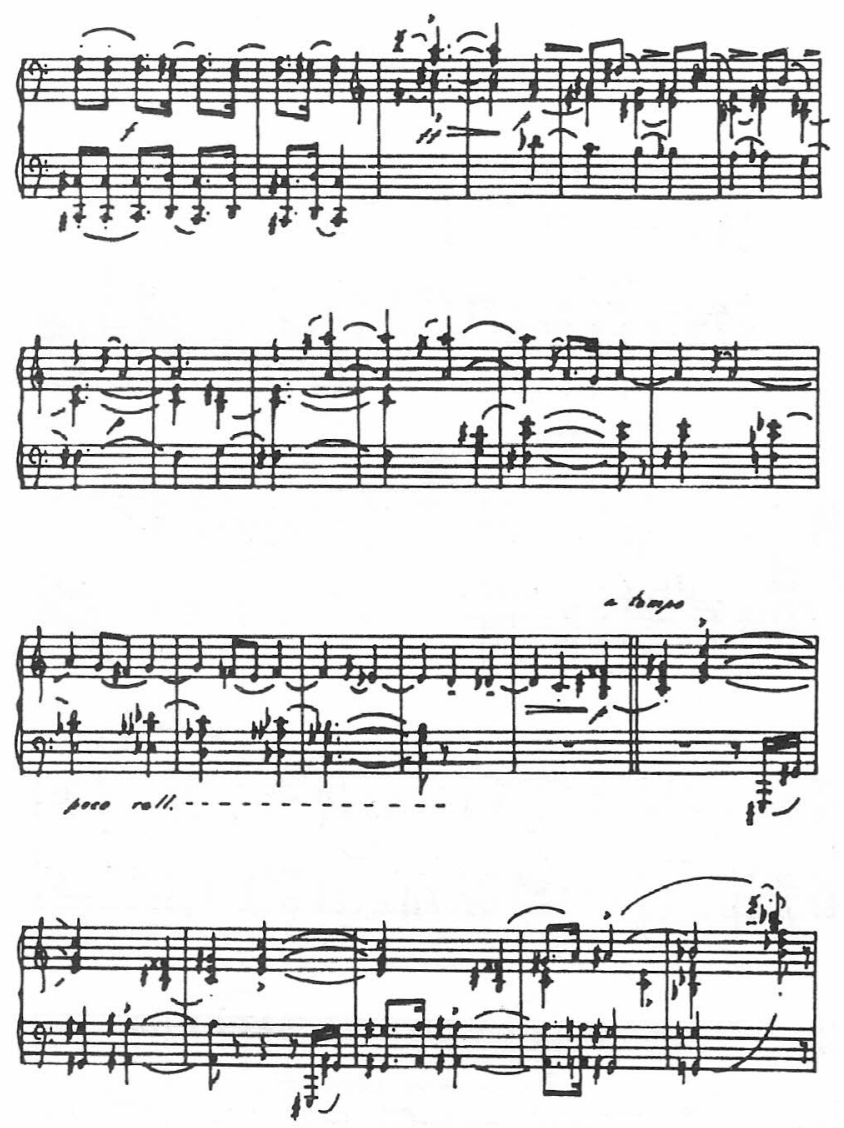

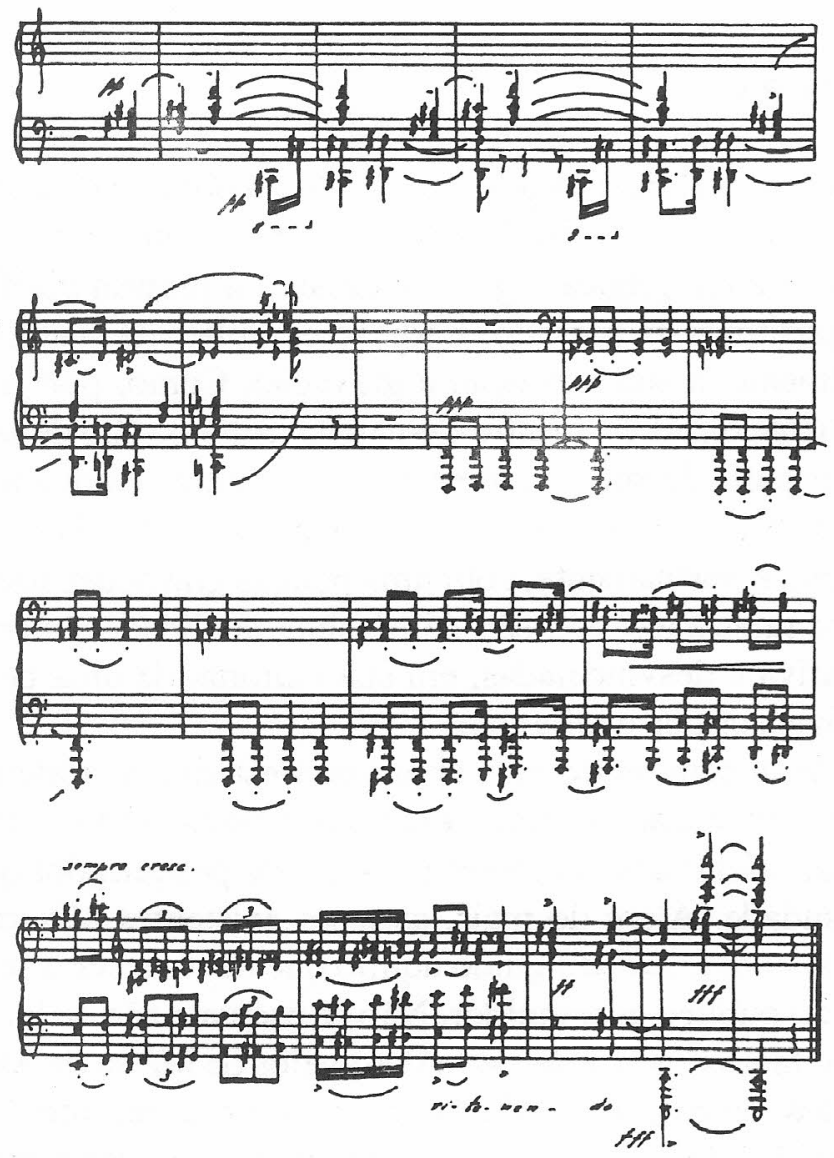